\title{
Book Review | Building Access: Universal Design and the Politics of Disability by Aimi Hamraie (University
}

\section{of Minnesota Press, 2017)}

\author{
Gracen M. Brilmyer \\ University of California, Los Angeles (UCLA) \\ gracenbrilmyer@gmail.com
}

For disabled people, ${ }^{1}$ how we see ourselves in history matters. Since the Americans with Disabilities Act (ADA) was passed in 1990, disability activism has often been remembered through highly visible public actions such as the Capitol Crawl and the Section 504 sit-ins. While these iconic moments-and the archives that document them-tell a crucial piece of our history, there are other narratives, often hidden or subtle in archives, that tell how our activism has historically worked under the surface or has been erased from popular cultural memory. Aimi Hamraie's Building Access: Universal Design and the Politics of Disability tells one such history: that of Universal Design, a flexible, inclusive design philosophy centered around accessibility for both disabled and nondisabled users. Universal Design, as it is understood today, is often framed simply and uncritically as "good" design for "everyone." However, Hamraie, through extensive archival research, locates less legible histories of disabled designers, activists, and architects who often get written out of the dominant narrative of the history of design and activism. Through this work, they complicate disability history, highlighting "the friction between liberal demands for compliance, productivity and assimilation and radical anti-assimilationist and crip methods of knowing-making the world"

Brilmyer, Gracen M. (2019). Review of Building access: Universal Design and the politics of disability, by Aimi Hamraie (University of Minnesota Press, 2017). Catalyst: Feminism, Theory,

Technoscience, 5(2), page 1-5.

http://www.catalystjournal.org|ISSN: 2380-3312

(c) Gracen M. Brilmyer, 2019 | Licensed to the Catalyst Project under a Creative Commons

Attribution Non-Commercial No Derivatives license 
(p. 99) that sometimes get smoothed over in legislation and in history. Building Access shows not only how people with disabilities were integral to contributing to, challenging, and pushing many design discourses forward but also how these stories of disability may be difficult to locate in the historical record.

Each chapter of Building Access exposes a constellation of histories that lead to the development of Universal Design. To make sense of these complex entanglements, Hamraie structures the chapters chronologically. Starting in the nineteenth century, the book begins by tracing the development of "normate templates": narrowly defined templates of users and inhabitants that designated how bodies should move and behave, often tied to whiteness, ableness, and citizenship. These templates produced spaces that excluded many types of bodyminds ${ }^{2}$ from public legibility. Hamraie then illustrates how the development of "flexible" design practices-such as ergonomics-although purporting to support multiple users, often aimed to normalize and optimize bodyminds for productivity .After complicating notions of "the user," Hamraie moves to analyzing design rhetorics that informed the early development of Universal Design, highlighting the integral work of disabled activism, crip epistemologies, and disability-centered rhetorics in the twentieth century. Emphasizing the friction produced by disabled activists - taking sledgehammers to curbs, creating interdisciplinary disabled maker cultures, and forming the independent living movement-Hamraie shows how disabled people were essential in pushing design pedagogy, accessibility standards, and legislation forward that led to the development of Universal Design.

In the present moment, the concept of Universal Design is multiply understood. Given its history in disability activism, the Principles of Universal Design can be applied as they were originally intended when coined by Ronald Mace in 1985: to anticipate flexible and equitable access for the most marginalized. Yet, as Hamraie points out, since disabled activists and designers strategically decentered disability to increase the popularity of accessible design, "It became possible to discuss Universal Design without reference to disability, while maintaining a focus on functionality and usability" (p. 226). When disability is left out of this history, the concept of Universal Design can be taken up by designers who interpret it simply as "good" design, neglecting needs specific to and discrimination against disabled communities. By centering the contributions of disabled people who influenced design discourse, and exposing how all design methods imagine the ways bodyminds could or should operate, Building Access illuminates how multiple knowledge creators with multiple political agendas can (intentionally and unintentionally) create fields of practice. 
One of the most remarkable aspects of this book is its methodology. By way of extensive archival research-from the Bancroft Library, which holds extensive records on disability activism, the Cooper Hewitt archives, and private collections from homes, basements, and offices-Hamraie locates a multitude of explicit and implicit narratives surrounding disability and design. They start with the location of an illustration of a single high-heeled shoe within an architectural diagram from the 1930s: a gendered trace that simultaneously unsettles the formerly unmarked male body of "the user" and yet illustrates a reliance on gendered, aesthetic, and calculable norms of user templates. This research shows how design practices can center, forget, and sometimes intentionally leave disability behind, while also assuming gendered, class, and racial norms. By drawing attention to these subtleties in records, Hamraie problematizes how design for, around, or without disability may reinforce notions of productivity, liberal consumerism, and citizenship.

Hamraie conducts such extensive archival research in tandem with performing and reflecting on what Karen Barad (2007) terms "agential cuts": drawing distinctions between ideas and discourses that also makes their differences appear meaningful. These combined techniques allow for Hamraie to read and reread archival records and expose conflicting and connected agendas in design. Hamraie uses the concept of agential cuts explicitly_drawing on Barad as well as what Thomas Gieryn (1983) calls "boundary work"3 - to develop the concept of "barrier work" in Chapter 6. Barrier work, Hamraie identifies, functions to define Universal Design as less about disability and more about common-sense "good" design for "everyone." And advocates of Universal Design used barrier work to distinguish Universal Design from barrier-free design, an ADA-rooted design strategy, which enforces minimal code compliance for accessibility. Through drawing their own distinctions while also historicizing how others have done so, Hamraie helps readers perceive that these two concepts of accessible design were engaged in mutual reiteration while being shaped for different purposes-barrierfree design for straightforward, minimal but implementable code compliance, and Universal Design for an expansive, interpretable, and disability-neutral notion of access.

Outside the chapter on barrier work, agential cuts are subtly performed throughout the entire text, to cut, bind, and surface such intra-actions: mutual reiterations between discourses, practices, ideas (Barad, 2007). Hamraie reads into the subtleties of archival records and provides us with complex, politicized narratives of design, while never leaving behind an analysis of how race, class, 
gender, and ability are continually mapped onto and embodied within design practices. Like the relationship between barrier-free design and Universal Design, Hamraie shows how concepts of user templates, consumerism, rehabilitation, and citizenship; practices of ergonomics, environmental design research, and accessibility legislation; and values of productivity, eugenics, performance, and justice have been and can be differentiated. Hamraie remarks, "We make them seem whole, coherent, and discrete when they are really quite unstable and complex" (p. 176). These agential cuts go unnamed in the majority of the text, but are still palpable as Hamraie draws, blurs, and historicizes distinctions between multiple material-epistemic arrangements. Given their subtlety, I'm left wanting more explicit theorization of how agential cuts are operating throughout the book. Because such cuts allow for an expansive and reflective rereading of disability history, a more explicit theorization could offer a methodological framework for other scholars to more easily apply to historical analyses. These cuts, alongside Hamraie's detailed archival research, allow for Building Access to rewrite and expand the history of disability activism, exposing how people with disabilities shape(d) and define(d) different design discourses not only by making disability a legible piece of the design process but also by subverting systems: decentering disability so that accessibility, packaged as "good design," could be encompassed within more mainstream design practices.

Furthermore, crip theory, like the feminist, queer, and critical race theories that Hamraie draws on, is deeply tied to practice. Thus, Building Access tells a new history not only of disability activism but also of the field of critical disability studies. Throughout the book, Hamraie illuminates how, just as design discourses intentionally or unintentionally decenter a politicized disability, so too does disability theory get taken up, reinterpreted, or misinterpreted within rehabilitative discourses. The agential cuts that Hamraie performs meaningfully reshape these interpretations to locate the slipperiness of our theories. For example, the social model of disability-which locates the "problem" within inaccessible buildings and discriminatory attitudes instead of strictly within the disabled bodymind-is often cited as a central concept within the fight for disability rights. However, what Hamraie's retelling shows us are the ways in which the social model has been simplified to overemphasize the environmental construction of disability, which fosters rehabilitative notions of eliminating disability through eliminating physical barriers.

To reread disability history, then, is to also reinterpret disability and crip theory in order to identify the textures, ways of navigating the world, and resistances that have been misinterpreted, intentionally reframed, built on, and accumulated 
within our environments and practices. Building Access shows not only how disabled people and their epistemic activism are (and have been) integral to the history of design but also demonstrates that historicizing the accumulation of knowledge is invaluable for telling our histories, surfacing power and privilege, and working towards justice.

\section{Notes}

${ }^{1} \mathrm{~A}$ note on language: I intentionally vacillate between using identity-first language and person-first language to reflect the complexity of how people identify within this community.

${ }^{2}$ The term bodymind is defined by Sami Schalk (2018) as "the inextricability of mind and body [that] highlights how processes within our being impact one another," specifically within the context of race, gender, and (dis)ability (p. 5-6).

3 Gieryn (1983) describes boundary work as the demarcation of science from nonscientific intellectual activities through boundary-making.

\section{References}

Barad, K. (2007). Meeting the universe halfway: Quantum physics and the entanglement of matter and meaning. Durham, NC: Duke University Press.

Gieryn, T. F. (1983). Boundary-work and the demarcation of science from nonscience: Strains and interests in professional ideologies of scientists. American Sociological Review, 48(6), 781-795. https://doi.org/10.2307/2095325

Schalk, S. (2018). Bodyminds reimagined: (Dis)ability, race, and gender in Black women's speculative fiction. Durham, NC: Duke University Press.

\section{Author Bio}

Gracen Brilmyer is a PhD Candidate in the Department of Information Studies at UCLA. Their research lies at the intersection of disability studies and archival studies, focusing on the role of disability within the history of natural history museums and their archives. For more: gracenbrilmyer.com 